\title{
Site LPO023 of Kurin: Characteristics of a Lapita Settlement in the Loyalty Islands (New Caledonia)
}

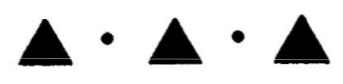

\author{
CHRISTOPHE SAND, JACQUES BOLÉ, AND ANDRÉ OUETCHO
}

FROM THE FIRST DATING by E. Gifford and R. Shutler Jr. in 1952, based on their excavations at Site 13 of the Foué peninsula in New Caledonia (1956), the chronology of production of the dentate-stamped Oceanic pottery tradition known as Lapita has been a subject of debate. During the last three decades, Lapita pottery has slowly seen its history shortened through various results obtained by different regional programs in the southwestern Pacific. Once believed to have lasted nearly the entire prehistoric chronology of Tonga (Golson 1971), or to have persisted over 1500 years in New Caledonia (Frimigacci 1999; Galipaud 1996), the Lapita chronology is today seen as limited to a few hundred years at most in Southern Melanesia (Bedford 2000; Sand 1997), and probably a few generations in Fiji and West Polynesia (Anderson and Clark 1999; Burley et al. 1999; Sand 2000b).

This recent shortening of the Lapita period serves to renew interest in Lapita as a firm archaeological signature of first Austronesian settlement in Remote Oceania. Comparison of the chronologies of Lapita sites archipelago-wide and region-wide can allow for a much more focused reconstruction of the directions of settlement and the speed of spread of the Austronesians throughout this previously empty region, some 3000 years ago. This type of analysis has recently been proposed for different parts of the Lapita sphere (e.g., Kirch 1997; Summerhayes 2000). In New Caledonia (Sand 1996a, 1997), the image identified is one of sets of large, early settled Lapita sites spanning the west coast of the Grande Terre around 1000 B.C., and then the southern tip of the archipelago. In this scenario, the place of the Loyalty Islands, located between southern Vanuatu and the Grande Terre, was confusing. The oldest dates obtained from the Loyalty Islands calibrated around 850 B.C. (Sand 1998a), about two centuries after the proposed first settlement dates for the Grande Terre. This implied a possible Lapita discovery of the Grande Terre directly from the southern Solomons or northern Vanuatu, with a later backwards movement toward the east to the Loyalty Islands.

Christophe Sand, Jacques Bolé, and André Ouetcho are affiliated with the Département Archéologie, New Caledonia Museum, Nouméa, New Caledonia.

Asian Perspectives, Vol. 41, No. 1 (C) 2002 by University of Hawai'i Press. 
Only a handful of classic Lapita sites have as yet been located in the different large islands of the Loyalty group (Anderson et al. 2001; Sand et al. 1999), with only three excavated before 1997, all with fairly late or confused dates (Sand 1995a, 1998a; Sémah and Galipaud 1992). As part of a rescue program conducted on the large bay forming the east coast of Maré, in Penelo district, a new excavation was conducted on a partly destroyed part of the sand dune area in 1997. The information presented in this paper, an understanding of the stratigraphy, analysis of the archaeological material, and firm dating of the different occupation layers, allow us to shed new light on the Lapita period of the Loyalty Islands, more in line with the data obtained for the rest of Southern Melanesia.

\section{THE RESEARCH AREA}

Maré is the southernmost island of the Loyalties (Fig. 1). The characteristic uplifted coral formation has a total land area of $642 \mathrm{~km}^{2}$ (approximately 25-by$15 \mathrm{~km}$ ), with a maximum elevation of $130 \mathrm{~m}$. The $8-\mathrm{km}-$ long dune region located at the foot of the uplifted reef on the east coast of Maré is rich in important early and late archaeological and traditional sites (Dubois 1970). Mentioned for the first time by the Marist priest Father Dubois in the 1960s, Lapita and postLapita sites scattered between Padewa, Patho, and Kurin (Fig. 2) have been poorly excavated to date. The Patho area is known in oral traditions as being the place of arrival of "Jams" from an island called $M a$, a metaphor for the arrival of a new group of people from somewhere in the region.

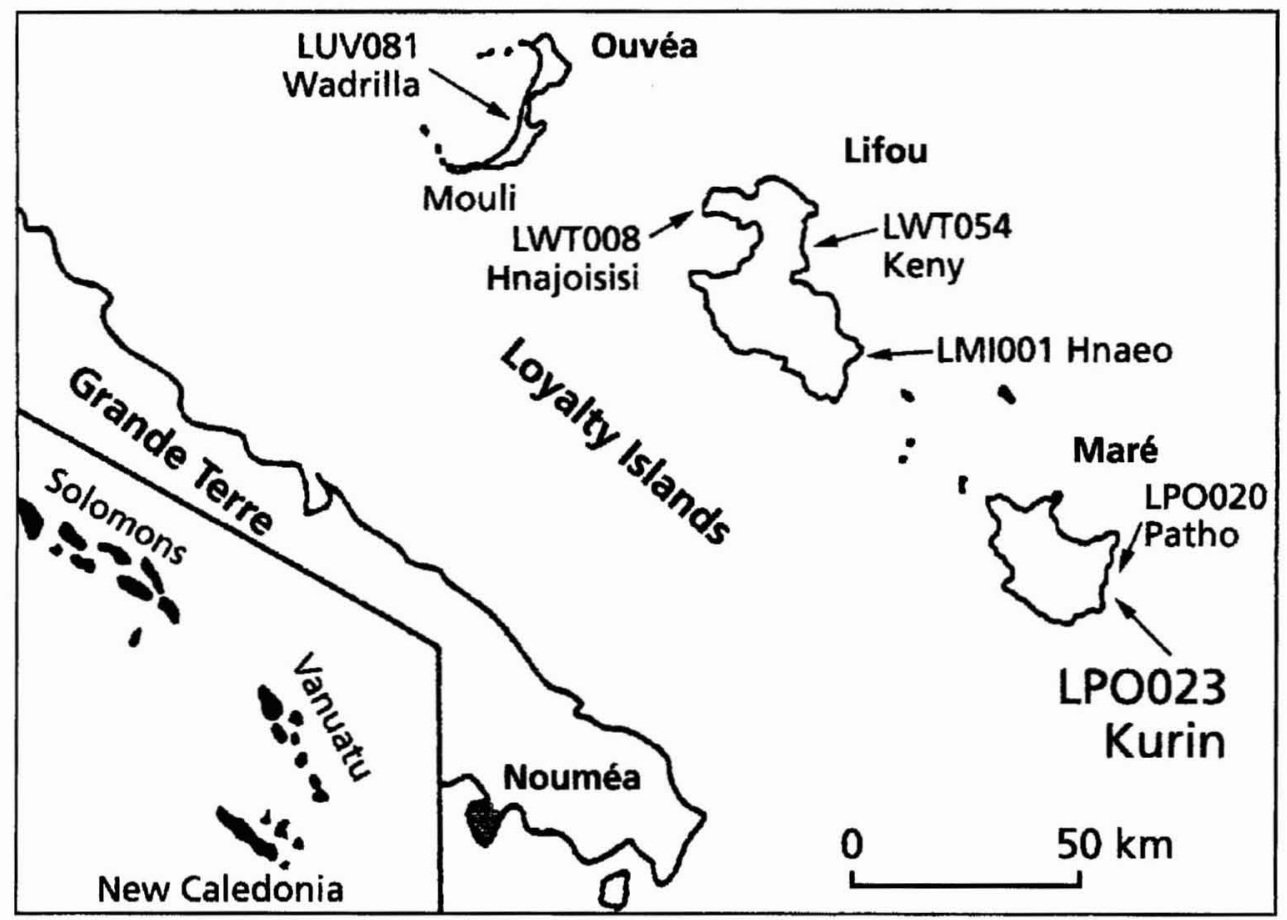

Fig. 1. Location of Maré Island in southern Melanesia. 
In 1986 and 1991, several weeks of excavation were conducted on site LPO020 (ex-LMA020) of Patho, located at the back of the dune system, showing the existence of an in situ horizon with material related to the Lapita Cultural Complex (Galipaud 1986; Sémah and Galipaud 1992). The oldest layer was dated by two samples, with results of $2590 \pm 110$ B.P. (ANU-6616), calibrated to 930 (795) 400 B.C., and $2500 \pm 90$ B.P. (Beta-50604), calibrated to 820 (630) 390 B.C. (Galipaud 1996). The excavators considered the site to have been occupied for a brief period about 2500 years ago (Sémah and Galipaud 1992). Subsequent synthesis of New Caledonian prehistory has identified this period as a time when the Lapita component had already disappeared on Grande Terre and Lifou Island (Sand 2000a).

Surface collections were made during the succeeding years by our department of archaeology on a nearby sand quarry, showing the existence of burials and anthropogenic layers with archaeological material of Grande Terre origin (pottery, stone beads, axes). ${ }^{1}$ A sample taken from the lowest anthropogenic layer of the formation returned a date of $1010 \pm 70$ B.P. (Beta-59960), calibrated to 890 (1020) A.D. 1205 (Sand 1995b), indicating a late formation of the dune system in the northern zone of Patho. During a field trip made to the dune region of Patho-Kurin in October 1997 by C. Sand with F. Wadra from the Provincial Yéwéné Cultural Centre, a recently cut roadway perpendicular to the dune was observed at a location called Lanijo. Lapita sherds were collected on the surface of the road and in the banks of the dune. Initial observation of the collection

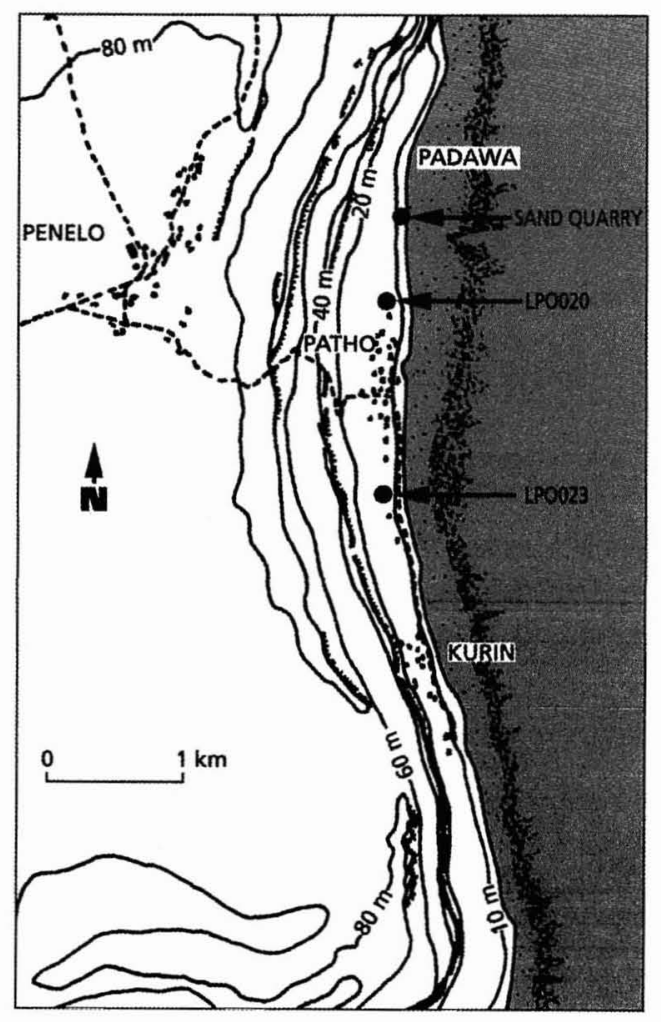

Fig. 2. Position of the different sites of the Penelo district discussed in the text. 


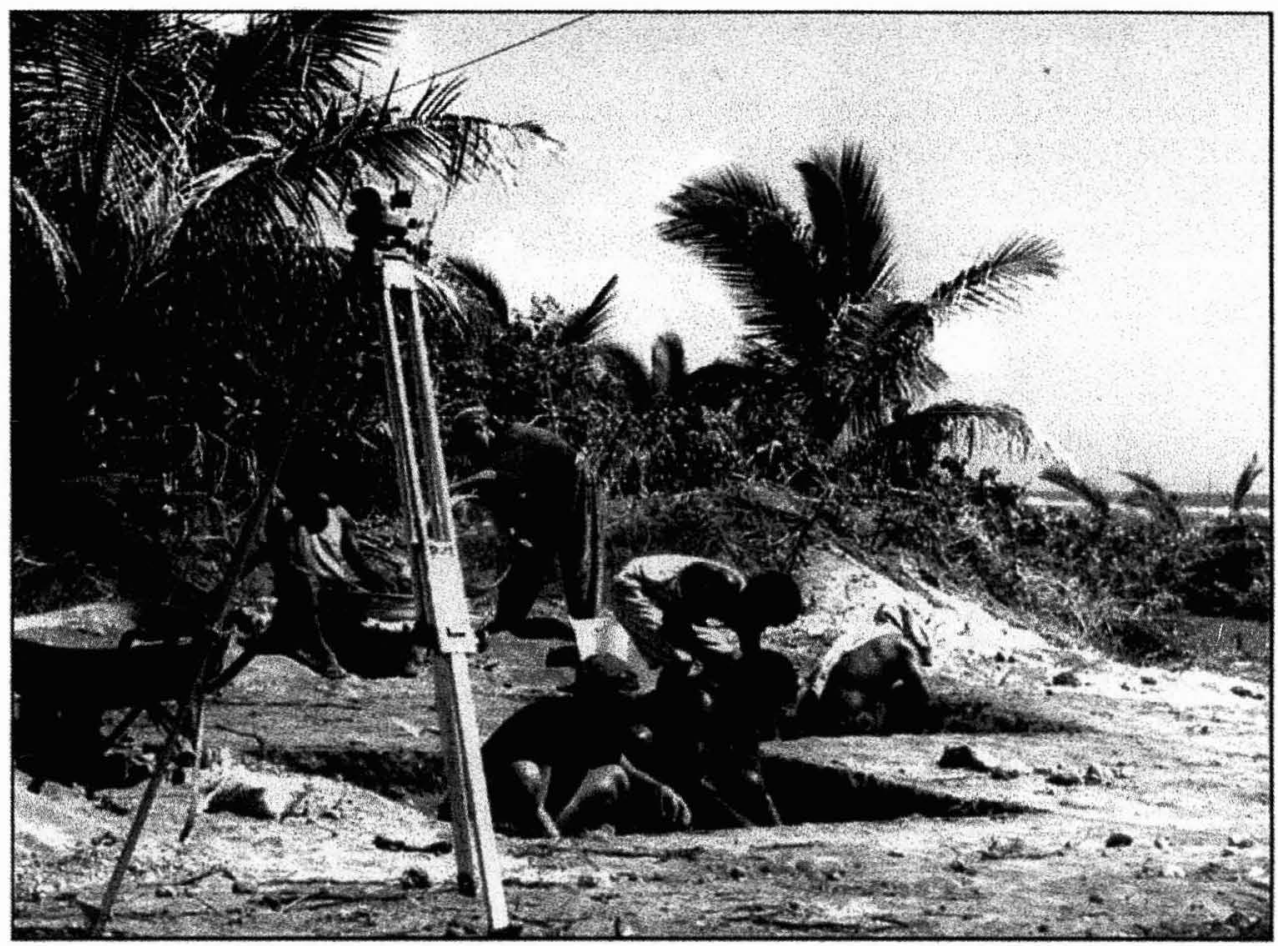

Fig. 3. Site LPO023 of Kurin under excavation, with the seashore area at the back.

revealed the presence of different dentate-stamped motifs and large fragments of one decorated pot. In order to better understand the richness of this part of the dune before further damage, a rescue excavation was conducted on the partly destroyed area of the site in December 1997.

The excavated site LPO023 is located in the northern part of the Kurin dune system. This area of the dune (Fig. 3), which is about $5 \mathrm{~m}$ high and $120 \mathrm{~m}$ wide, is located in front of a $200-\mathrm{m}$-wide fringing reef with a shallow lagoon in some places, which breaks most of the wave formations from the ocean before they arrive on the beach. This part of the dune is being eroded, partly through the action of the strong prevailing winds blowing from the southeast. In this part of the dune system, the archaeological levels are located on top of the dune, just at the back of the road, about 40-50 $\mathrm{m}$ from the present seashore (Fig. 4).

\section{EXCAVATIONS}

A first cleaning of the nearly $100 \mathrm{~m}^{2}$ of bulldozed area before grid positioning showed that in the zone located toward the northeast, the archaeological layers had been completely removed during the construction of the road leading to the back of the dune. Attention was concentrated on the upper part of the area, where the in situ layers seemed still to be present. A grid of 6-by- $8 \mathrm{~m}$ was put in place, with an orientation perpendicular to the main road (northwest-southeast). 


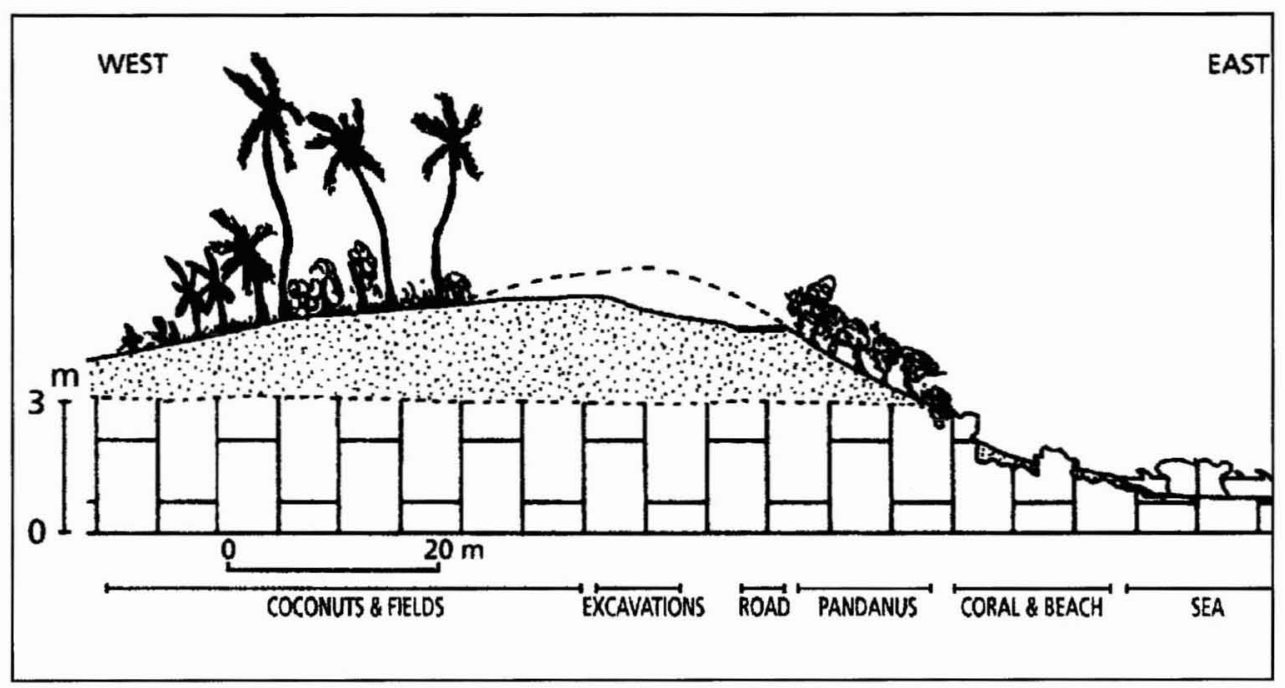

Fig. 4. Profile of the dune at LPO023.

Only two 2-by-2-m squares were excavated in 1997, labeled respectively Squares $\mathrm{B}$ and $\mathrm{F}$.

\section{General Stratigraphy}

The excavation of Squares B and F, located on the upper part of the truncated dune, has exposed archaeological layers up to a depth of $80 \mathrm{~cm}$ (Fig. 5).

Layer 1, present only in the western part of Square B, with a maximum depth of $15 \mathrm{~cm}$, is the remains of a carbonized sand horizon, probably indicating the former nearby presence of an oven. This layer was nearly completely removed by the bulldozers, but the presence of some non-Lapita sherds of Néra tradition point to a setting probably during the last 1000 years (see below for dating). The

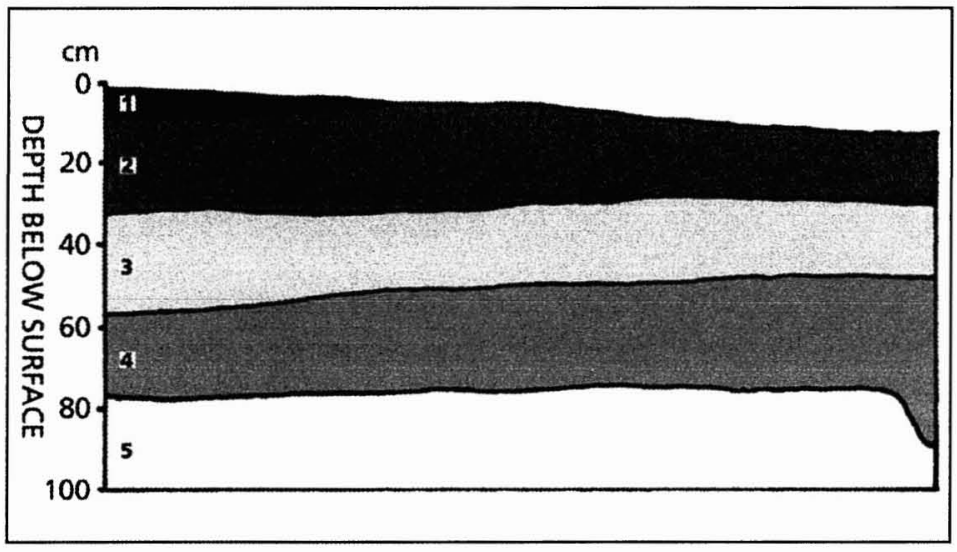

Fig. 5. Stratigraphy of Square B. 


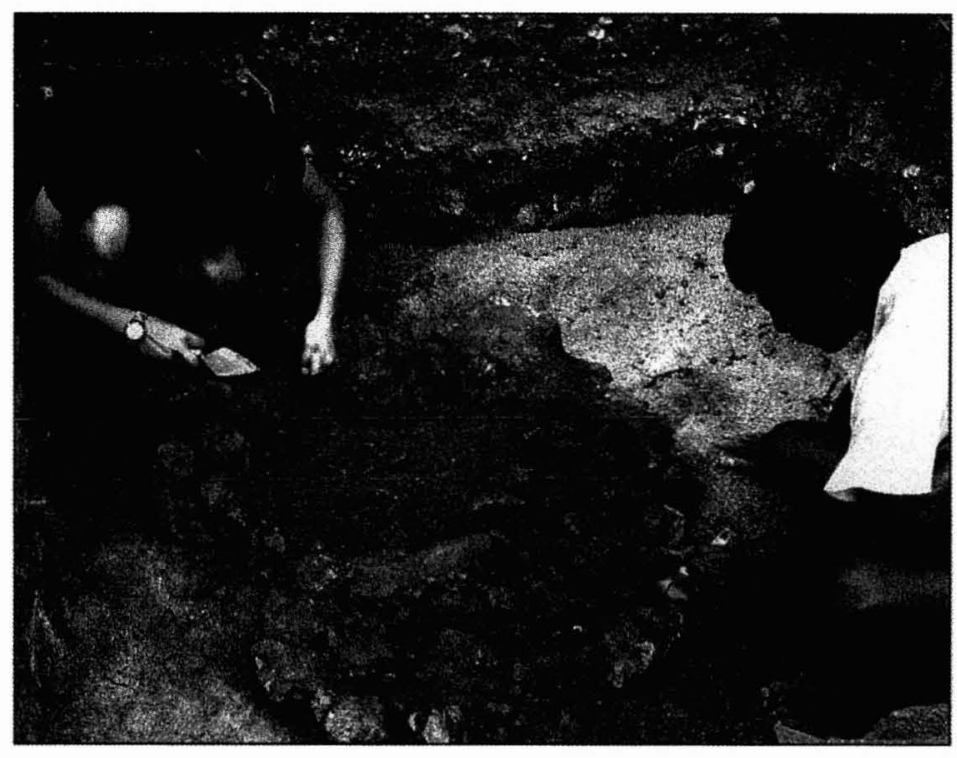

Fig. 6. The oven discovered in Layer 4 of Square B during excavation.

few sherds tempered with coral sand are of small size and weathered, indicating the action of low-scale redepositional processes.

Layer 2 is a sandy dark-brown fill about $20 \mathrm{~cm}$ thick, with very little archaeological remains. Its formation is probably the result of natural processes. The few small sherds found in this layer are eroded.

Layer 3, about $20 \mathrm{~cm}$ thick, is composed of light-brown sand, with the first appearance of orange-colored pumice and the first concentration of urchin spines. The amount of potsherds and shells increases dramatically. No stratigraphic disruption between Layers 3 and 4 has been observed, possibly indicating a continuous formation process.

Layer 4, forming the base of the anthropogenic stratigraphy, is a gray sand, with a thickness between 20 and $25 \mathrm{~cm}$ in Square B but nearly absent in Square F. The presence of sherds with old breaks, which fit together, speaks to low postdepositional disturbance. A posthole has been identified in the northeastern wall of Square B. In the center of Square B, at the base of the layer, we excavated an oven of coral blocks about $35 \mathrm{~cm}$ deep and $60 \mathrm{~cm}$ in diameter, with a further extension of burned coral to the east for another $50 \mathrm{~cm}$ (Fig. 6). Some large but fragile burned sherds and long bones were found in the oven, but little charcoal was present in the fill. In order to preserve part of the structure for possible future reanalysis, the oven was not completely excavated.

Layer 5 is a white sand formation, archaeologically sterile, with yellow and orange pumice and small coral blocks. The excavation ended on this layer.

The same general stratigraphy, over $1 \mathrm{~m}$ thick, was recorded on the bank of the preserved dune to the southeast of the excavations, with Layer 1 up to $35 \mathrm{~cm}$ thick. During the cleaning of about $8 \mathrm{~m}$ of profile we observed that there is an inland downward direction to the layers, contrary to the present-day situation where this part of the dune surface layer is oriented downward toward the sea. 
Table I. The ${ }^{14}$ C Dates from Site LPOo23 of Kurin

\begin{tabular}{|c|c|c|c|c|c|}
\hline CONTEXT & $\begin{array}{l}\text { LABORATORY } \\
\text { NUMBER }\end{array}$ & $\begin{array}{c}\text { MEASURED }{ }^{14} \mathrm{C} \\
\text { AGE }\end{array}$ & $\begin{array}{l}{ }^{13} \mathrm{C} /{ }^{12} \mathrm{C} \\
\text { RATIO }\end{array}$ & $\begin{array}{c}\text { CONVENTIONAL } \\
{ }^{14} \mathrm{C} \text { AGE }\end{array}$ & 2-SIGMA CALIBRATION \\
\hline Layer 1 & Beta-118336 & $420 \pm 90$ в.Р & $-26.0 \%$ & $400 \pm 90$ в.P & $1400(1470)$ A.D 1665 \\
\hline Layer 3 & Beta-125141 & $2660 \pm-60$ в.Р & $-24.4 \%$ & $2670 \pm 60$ в.Р & 915 (815) 780 в.С \\
\hline Layer 4 & Beta-125142 & $2940 \pm 60$ в.Р & $-27.9 \%$ & $2890 \pm 60$ в.Р & $1260(1030) 905$ в.с \\
\hline Layer 4 & Beta-118334 & $2960 \pm 110$ в.P & $-27.0 \%$ & $2920 \pm 110$ в.Р & $1410(1110) 825$ в.С \\
\hline Stone oven & Beta-118335 & $2960 \pm 60$ в.Р & $-28.5 \%$ & $2900 \pm 60$ в.Р & 1265 (1045) 910 в.С \\
\hline
\end{tabular}

This means that when the early layers were formed, the dune was larger and higher toward the sea. It extended more than its present-day position, and the settlement was farther back from the seashore and more protected from the prevailing winds than today. During the recent millennia (probably the last 1500 years), erosional processes have slowly moved part of the sand of the Kurin dunes toward the Patho dunes to the north, creating the archaeological layers dating from 1000 B.P. onward in the Patho sand quarry (Sand 1995b). The contemporary configuration of the dune is thus relatively recent.

\section{RADIOCARBON DATING}

One of the central objectives of the excavation conducted on site LPO023 of Kurin was to evaluate the representativeness of the dates obtained on the neighboring site LPO020 of Patho (Sémah and Galipaud 1992) in order to gain a better idea of the chronology of Lapita settlement in the Loyalty Islands. To date, five ${ }^{14} \mathrm{C}$ dates have been obtained for site LPO023, all from Square B, where the best identified stratigraphy has been observed. The youngest date comes from Layer 1 , with a result calibrated to 1400 (1470) A.D. 1665 (Beta-118336). This date is in perfect agreement with the Néra pottery type found in Layer 1 . The upper part of the Lapita occupation, in Layer 3, was calibrated to 915 (815) 780 B.C. (Beta125141, AMS). The upper part of occupation Layer 4 was calibrated to 1260 (1030) 905 B.C. (Beta-125142, AMS). The lower part of Layer 4 was calibrated to 1410 (1110) 825 B.C. (Beta-118334, extended counting time). Finally, the stone oven at the base of the stratigraphy was calibrated to 1265 (1045) 910 B.C. (Beta118335, AMS).

Once calibrated, and considering the large probability range of sample Beta118334 , these dates give a chronology of Lapita occupation of Layers 4 and 3 spanning the period between c. 1050-1000 B.C. and 850-800 B.C., well in accordance with the Lapita chronology proposed for the rest of New Caledonia (Sand $2000 a$ ). This is followed by a much more recent occupation of the upper part of the dune in the mid-second millennium A.D., associated with Néra tradition pottery (Sand 1995b).

\section{MATERIAL CULTURE}

During the excavation, all the sediments were sieved through 3-mm mesh on site. The material was divided into potsherds, shell objects, stone flakes, shells, and bones, each discussed separately below. 


\section{Ceramics}

After initial cataloguing on site, the ceramic material was desalinated in the laboratory for preservation (Coote and Sand 1999) before study. A total of 550 sherds have been identified in the excavation, plus more than 500 collected on the surface. The collection is very fragile due to the massive use of coral temper and low firing of the pots: sherds often tended to break into pieces during excavation and lab pretreatment. Taking these points into account, medium sherd surface area (normally between $4 \mathrm{~cm}^{2}$ and $6.5 \mathrm{~cm}^{2}$ ) indicates good preservation of the material and low post-depositional reworking of the layers. In different instances, sherds of the same pot could be fitted together.

Most of the material is concentrated in Layers 3 and 4. Apart from some Néra tradition sherds of southern Grande Terre origin, discovered in the upper part of Layer 1 of Square B, all the material is related to the pottery tradition of the Lapita ceramic series, with sherds formed by a sometimes extensive amount of coral sand temper, suggesting predominantly local production of the pots (Dickinson, pers. comm. 2001). The presence of lithic temper in a few sherds found during surface collection on site LPO023, and also excavated in the nearby Patho site (Galipaud 1990), point to the existence of low-frequency interisland exchange, with the production or collection of raw materials outside the Loyalty Islands.

Most of the rims are out-curved with a flattening of the lip (for example, Fig. $7 \mathrm{~d}-\mathrm{f}$ ). One double rim is related to a dentate-stamped pot (Fig. 9c). Nearly all the rims are decorated, with full or dentate stamped impressions, or incisions. Some rims are very out-curved and correspond probably to plates, dishes, or lids (Fig. $7 \mathrm{~g}-\mathrm{i}$ ), although no clear flat-bottom vessel form has been identified. In the upper part of the Lapita horizon, the rims tend to be more moderately out-curved (Fig. $7 a-c)$. The presence of light carinations shows the production of composite vessels, mostly decorated. Rim size variation indicates pots of different shapes, some probably not exceeding $15 \mathrm{~cm}$ in diameter and characterized by very small rims ( $<3 \mathrm{~mm}$ thickness). Some sherds show construction by the slab-building technique, with brushing or slipping of the outer surface. About 15 different pots

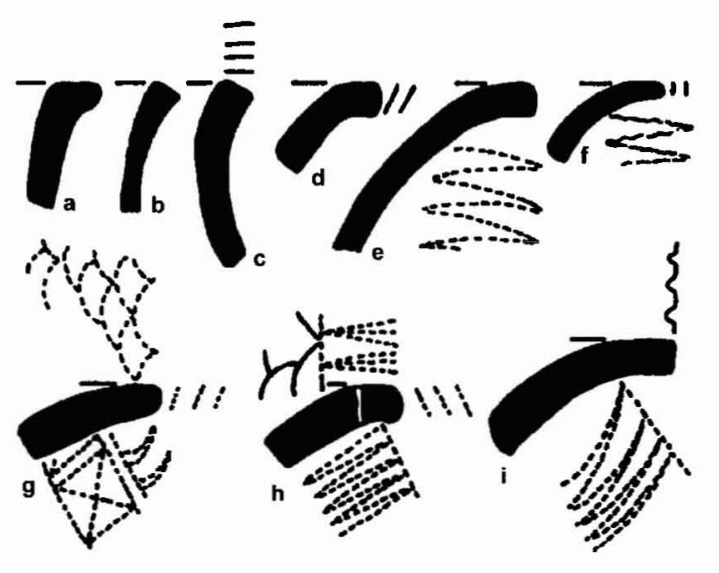

Fig. 7. Examples of rim profiles from the ceramic material of LPO023 (described in text). 
have been identified in the surface collection, and 9 pots are reconstructible from the excavated material (Figs. 9-10).

If the number of excavated sherds is taken into account, about one-fourth of the potsherds are decorated, but this proportion rises to nearly half of the collection if the surface of the sherds is taken into account. Two major types of decorations have been identified in the Lapita horizon: dentate-stamped and impressed. The dentate-stamped motifs account for about half of the decorated sherds found in the excavated units (54 percent in Square B and 45 percent in Square F) (Fig. 8). Attention is drawn to the difference in the size of punctations ("dots") between different decorated pots, indicating the existence of different sets of tools. The small size of some of the sherds discovered limits the identification of motif. The most present motif is simple, formed by the undulations of a crescent-shaped tool horizontally or vertically, or both, to stamp a series of zig-zag patterns (Figs. 8f-h, 9a-b). Other simple motifs are more classic parallel rows of vertical lines and successive triangles (Fig. 8a-d). Apart from the zig-zag motif, about 20 sets of partly complete motifs have been identified. Some pots bear a simplified elongated face motif with a cross replacing the eye (Figs. 8i-k, 9c). In Square F, a similar figure with a crescent construction replacing the eye has been found (Fig. 81). The pot reconstructed from sherds collected on the surface bears a complex triangular motif divided by parallel vertical bands (Figs. 8m, 9d). Other triangular motifs are present on poorly preserved sherds from the excavation (Fig. $8 n-0)$. Eight out-curved rims bear a motif on the inside lip, one having two small perforations running perpendicular to the sherd (Fig. 7h). In only two instances have more complex, rounded motifs been identified, without being able to reconstruct the complete design. Pots had, in conjunction to classic triangular and crescent-shaped motifs, needle-points made between the dentate-stampings (Fig. $8 \mathrm{a}-\mathrm{b})$. In one instance, a dentate-stamped parallel motif and a crescent-shaped printed motif (discussed next) are present on the same pot.

The second type of decoration is composed of the simple zig-zag motif, made
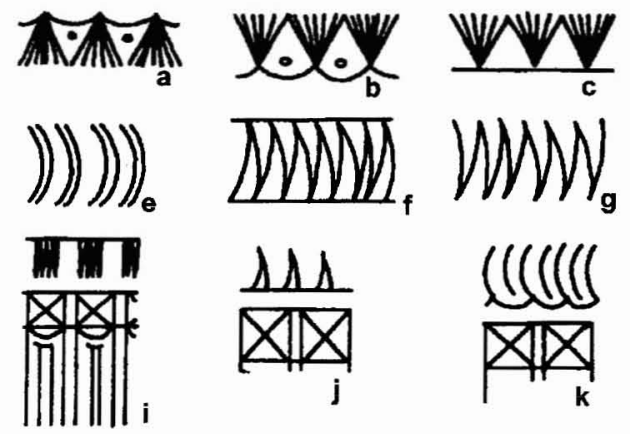
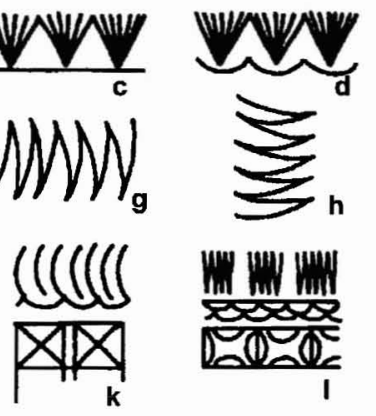

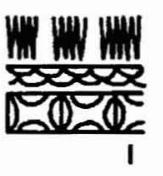

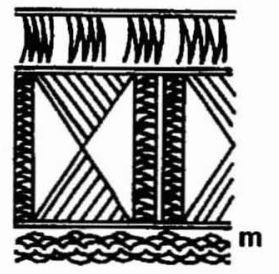
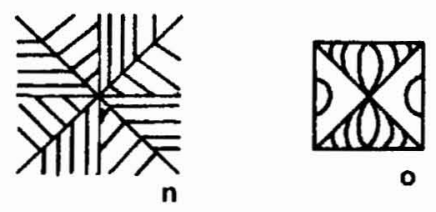

Fig. 8. The major dentatestamped motifs listed from site LPO023 (described in text). 

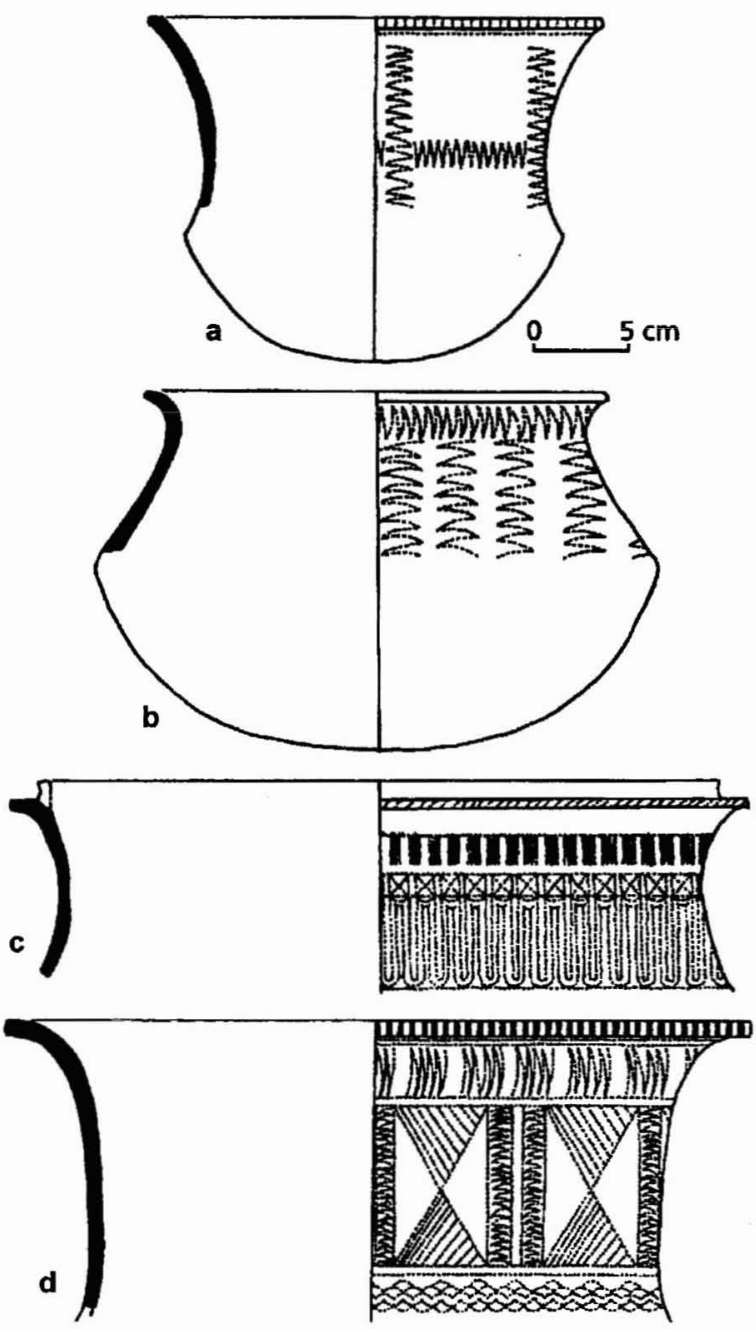

Fig. 9. Reconstructed dentate-stamped decorated pots from site LPO023 (described in text).

on the surface of the pot by the imprinting of a nondentate tool. Some stampings are deep while others are very light. The classic pot form is one of a light carinated, round-bottom ceramic with an out-curved stamped rim (Fig. 10c). This rather unique type of decorative technique had previously been identified in Lapita settlement sites of the Loyalty Islands, on Lifou (Hnajoisisi and Keny) (Sand 1995a) as well as Ouvéa (Sand et al. 2001). The significant presence of this technique in the Kurin site reinforces the hypothesis of a local development of this Lapita style in the Loyalties, in proportions not yet observed in contemporaneous sites on the Grande Terre.

Only about 15 sherds, representing very few pots, have a simple shellimpressed decoration, mostly in the form of zig-zag undulations. In one instance, shell and plain impressions appear on the same pot (Fig. 10b). Significantly, only one pot has a classic Lapita incised pattern, others having only a notched lip (Fig. 10a). Paddle impression is also rare, appearing on only two sherds late in the sequence. Only one pot in the collection is completely devoid of decoration. 


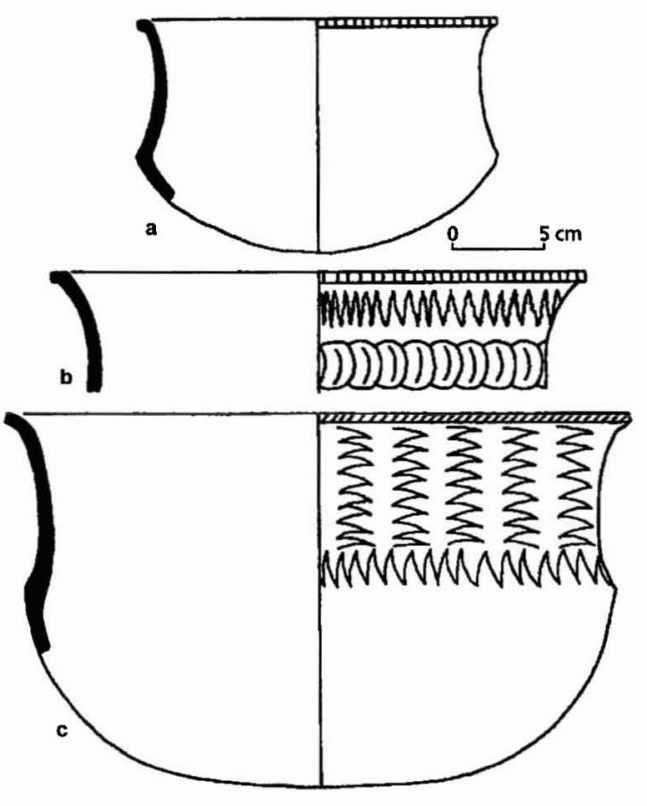

Fig. 10. Reconstructed pots with nondentate tool impressions from site LPO023 (described in text).

\section{Shell Objects}

Only two tools made of locally available material have been identified, from Layer 3 of Square F: one is a polishing tool made out of a stalactite, the other is a damaged Tridacna adze preform. Ornaments are also rare, coming from Layer 3 of Square B. One cut upper part of a Conus shell, and one piece of waste cut from a lower part of a Conus shell used for a ring are the only large manufacturing remains identified. Only one small shell bead was found: it is the first object of this type identified in a Lapita context for the Loyalty Islands. What is probably the most interesting discovery is a nearly round Tridacna disc found in the surface collection, about $3 \mathrm{~mm}$ thick and $2.5 \mathrm{~cm}$ in diameter, possibly used in an ornament or on a sculpture.

\section{Lithic Material}

Only 12 rock flakes in types of siliceous rock like phtanite, red jasper, and a sort of chert have been found in the two excavated squares. These are mostly small flakes without clear form, probably coming from debitage waste. To be noted nevertheless are two points of the same general shape as points found in the St. Maurice-Vatcha Lapita site on Ile des Pins (Sand 1999a). A fragment of a polished adze and one flake made from a green stone of an unidentified type, common to the Lapita adzes used in New Caledonia (Sand 2000a), have been found in the lowest layer of Square F. A fragment of gabbro polishing stone was found on the surface of Square F, possibly coming from the post-Lapita layer, and one in Layer 3 of Square B. All this stone material is most probably of Grande Terre origin, indicating relationships between the Kurin site and other Lapita sites of the Archipelago. 


\section{Floral and Faunal Remains}

Fauna-The faunal remains, in low quantity, are mostly restricted to fish bones which have been identified by F. Leach. A few very damaged long bones, probably from the flying fox, were found in the stone oven. No rat or bird bones are identified in the collection. The MNI of the fish bone collection is 12 , with a NISP by family of 19. Fifty percent of the identified fish bones come from Scaridae, followed by an equal number of identifications of Diodontidae, Coridae/ Labridae, and Balstidae. All these fishes would have been easily caught on the reef in front of the site, most probably by angling, spearing, or netting. Notable is the presence of several elements of a Teredidae barnacle, a ship worm. The study of these remains is still underway.

Shells - The sorting out of the shell material was made in different stages. The first division was between bivalves, gastropods, land snails, and sea urchin spines, all of which were weighed. The unidentifiable residues totaled 4 percent in Square B and 16 percent in Square F, indicating a low post-depositional disturbance, as had already been demonstrated by the study of the pottery. In the Lapita horizon, the gastropods account for approximately 50 percent of the total collection of shells. The bivalves represent between 7 percent and 8 percent. The land snails make around 15 percent of the total in Square B but over 25 percent in Square F, a reverse situation from the sea urchins, which represent 25 percent in Square B but only 2.5 percent in Square F. The amount of collected sea urchin and land snails in the Lapita horizon is significant, showing a diversity of species taken. Horizontal distribution shows, for the Lapita horizon, a lower density of shells in Square B than in Square F, which has a density of shell over $30 \mathrm{~kg} / \mathrm{m}^{3}$ in Layer 3. Vertical distribution shows, from bottom to top of Square B, a shell density of around $6.5 \mathrm{~kg} / \mathrm{m}^{3}$ for Layer 4 and around $20 \mathrm{~kg} / \mathrm{m}^{3}$ for Layer 3, possibly indicating an increase of gathering and density of occupation.

The difference between gastropods and bivalves in this site is strong. Bivalves account for just over 10 percent of the seashells, and are composed of over 80 percent of heavy Tridacna maxima remains, representing only a few individuals. The harvesting was thus nearly entirely devoted to gastropod collection, which is in agreement with the type of fringing reef seashore present in front of the site. Four species comprise over 95 percent of the catch: Turbo argyrostomus ( \pm 50 percent), Trochus niloticus ( \pm 40 percent), small-sized Turbo sp. ( \pm 4 percent), and Cellana radiata (Patellidae) ( \pm 3 percent). Eleven other gastropod species have been identified in the material, but represent probably more opportunistic gathering.

\section{DISCUSSION}

The field program carried out in December 1997 on site LPO023 of Kurin has allowed us to identify an in situ Lapita horizon on top of the sand dune. As part of a rescue excavation, the aim of this program was to obtain a clearer picture of the characteristics and chronology of this settlement in order to gain a better knowledge of the local development of the Lapita Cultural Complex in the Loyalty Islands.

The natural environment of the east coast of Maré Island is markedly different from the usual type of inner lagoon, seashore locations found on the west coast of 
the Grande Terre of New Caledonia (Sand 1995b). The beach is only partly protected from the open ocean by a medium-sized reef platform, rich in marine life. Easy access to the sea is possible farther north of the bay (in front of the presentday sand quarry), where fresh ground water has prevented the coral growth, forming a small pass in the reef. Significantly, the type of natural setting present on the east coast of Mare is similar to those observed on the other well-defined Lapita sites of the east coast of Lifou Island, on the dune formations of LWT054 around Keny and LLI002 of Hnaeo (Sand 1998a). This shows a tradition of seashore settlements in front of fringing reefs clearly present during the first phase of Austronesian settlement in Southern Melanesia (Sand 1995a), and not only one of barrier-reef protected, shallow bay occupations (Frimigacci 1980). This identification of another type of natural environment where Lapita sites occur in New Caledonia is important, as it opens whole new opportunities of locating large early settlement in locations deferring from the "classic" Lapita environment, especially on the east coast of the Grande Terre (see Sand et al. 2001).

The location of the Lapita occupation layer of site LPO023 on top of the dune formation of Kurin differs markedly from the data obtained nearly fifteen years ago on the neighboring site LPO020 of Patho, which is located at the back of the dune. The analysis of the stratigraphic profiles and the comparison of our results with the data from the other sites studied in the bay seem to confirm a post-Lapita movement of part of the dune from the southern part of the coast at Kurin toward the north, in Patho. The present-day environment is therefore markedly changed from what the seashore looked like around 3000 years ago, with a higher, larger dune in the south, where the Kurin location is, and possibly an absence of a high dune around Patho, which could have been used more in relation to the access to the open sea, as a canoe area for example.

The ceramic material discovered on site LPO023 indicates the presence of a rich and diversified Lapita occupation. The amount of decorated versus nondecorated sherds, not counting the rims, shows that probably nearly every pot was decorated, if we accept that the lower parts of the dentate-stamped pots were plain, and that part of the small nondecorated sherds may be from the large spaces present between the simple zig-zag motifs. This is an important result, although it gives no information on the differential uses of the variously decorated pots. This site is one of the few instances where good preservation helps to identify the nondentate-stamped part of the Lapita ceramic series. The carinations present in the collection are poorly angled, and should be labeled as shoulders. Most of the pots were probably of a globular form with light shouldering and rounded bottoms. Very few flat bottoms have been identified in the collection.

A number of classic geometric dentate-stamped motifs showing a tendency toward open decoration, and already mostly identified in other Lapita settlements of southern Melanesia, have been identified for site LPO023. A new large triangular type of motif with vertical divisions has been added. Especially notable is the complete absence of the classic Western Lapita division marker. Although the ceramic collection is small, compared to sites such as WKO013A (Sand 1998b), we can attempt to place the Kurin pattern within a larger chronological framework, as has been achieved in other Melanesian sites (e.g., Kirch 1997; Summerhayes 2000). Judging from Square B, it appears that we have in Layer 4 more dentate-stamped Lapita sherds compared to Layer 3, with an over-representation 
of simple zig-zag motifs on the sherds in the upper part of Layer 3. The same general tendency appears in Square F. Significantly, about 50 percent of the decorated sherds in this site are characterized by full-stamped motifs made in the same way as the dentate-stamped motifs. Although the regional database is still restricted to a few sites, it more and more appears that this is a Loyalty Islands characteristic that is part of the Southern Lapita Province. Interestingly, the full stamped tradition and its unique zig-zag pattern seem to be present from the early settlement phase onward, as if the local technique had rapidly been adopted region-wide. In conjunction with the large amount of coral temper, the specific clay leading to a red-brown color and the light carinations, these full stamped motifs allow one to readily identify Loyalty Island pots in Lapita collections from the Grande Terre, as on site SGO015 of Goro on the southeast coast (Sand et al. 2001). The reason(s) for the disappearance of the combs on the decoration remains unanswered, but might be related to the total absence of stone in the Loyalty Islands to make the fine combs, and the need to import them from the Grande Terre. One similarly decorated sherd has been identified by R. C. Green and D. Anson in the Lapita collection of site SAC in Watom (2000:76), and future studies might show a low presence of this type of decoration in other Lapita sites of central Melanesia. From Anson's region-wide motif study, the zigzag pattern seems to be restricted to the Eastern Lapita Province and Malo (Anson 1983, motifs 267-269), although a similar pattern, dentate stamped, is also present in site WKO013A.

The amount of incised, impressed, or dentate-stamped rims in this site, nearly 100 percent, is unique at present for New Caledonia. Interestingly, the Arapus pots illustrated by S. Bedford, identified as the functional pottery of a 3000-yearold Austronesian settlement in central Vanuatu, is also composed of only decorated rims (Bedford 2000: figs. 7.5, 7.6). Although some thicker, possibly bottom portions of pots have a darker outside, no identification of use of fire has been made for the entire collection.

Notable is the near complete absence of paddle-impressed, Podtanean tradition pottery in the excavated part of the site, comprised of only two sherds in the upper part of Layer 3. Two paddle-impressed sherds have been found during surface collection on the neighboring site LPO020 of Patho (Sémah and Galipaud 1992:13), but without clear relationship at present to the Lapita layers. This absence is important, as it points to a tradition of mostly smoothed or slipped pots for utilitarian use in conjunction with the dentate-stamped Lapita pottery at first settlement, slowly replaced in New Caledonia by a growing proportion of paddle-impressed pots during the local chronology of the Lapita phase (Sand 2000a), with its major significance later during the Koné period (Sand 1999b). The hypothesis of a local New Caledonian development of the paddle-impressed pottery tradition from the Lapita period on, is reinforced by the total absence of paddle-impressed pottery in contemporaneous sites in Vanuatu (Bedford 2000; Galipaud 1999). From current archaeological data, it appears that the development of the Podtanean tradition on the Grande Terre, and the trade of pots to the eastern part of the archipelago during the rest of the first millennium B.C. (Sand 1998 b), led to the end of local ceramic production in the Loyalties.

The amount of nonceramic material is low, comprising mostly production 
waste of ornaments known in other classic Lapita sites, such as Conus shell rings and drilled beads. The presence of small-size stone flakes of Grande Terre origin, with the identification of two possible drill points, points anew to the existence of a regional network during the Lapita period in New Caledonia. To be noticed is the fairly important amount of red jasper in Square F, characteristic of Lapita sites from north of Grande Terre. This indication of links between Maré and the northern part of the archipelago from the beginning of the first millennium B.C., also indicated by ceramic studies (Galipaud 1990:140; Sand 1998a:199), is important, as it appears to be the only regular direction of interaction during the second part of the first millennium B.c. (Sand 1999b:153). The discovery of a fragment of a green-colored polished adze and a flake of the same rock reinforces the view that this type of as yet unsourced stone was the characteristic rock used region-wide during the Austronesian spread (Green 1992).

Lapita period sea harvesting has been characterised in most of the early sites of Melanesia as a fairly unsystematic collection of varieties of shells from the nearby sea areas (e.g., Green and Anson 2000; Swadling 1986). The concentration, in site LPO023 of Kurin, of shell-fish harvesting on only two major species, Turbo and Trochus, shows on the contrary a fairly focused attention in collecting primarily these two genera of gastropods. Not surprisingly, the overrepresentation of gastropods versus bivalves in this site has to be related to the particular type of fringing reef environment present in front of the dune system. These results are in marked contrast to what has been identified in the Lapita sites of the Grande Terre and Ile des Pins, where the majority of the shells collected were bivalves (i.e., Sand 1998b, 1999a), living in the nearby sandy and marshy environments characteristic of those locations.

The large amount of sea urchins in the Lapita horizon, and the near total absence of these in the upper part of the stratigraphy, shows a strong interest of the first Austronesians settling in the Loyalty Islands on this sea product. Excavations conducted in the neighboring island of Lifou have also shown a dense concentration of sea urchin remains in the lower layers of different first millennium B.C. sites, followed by a near disappearance of this catch in later horizons (Sand 1998a). The same can be said for the land snails, present in all the Lapita sites of the archipelago, but whose consumption has been less important in more recent periods.

The progressive augmentation of shell density in the stratigraphy probably marks a slow intensification of human occupation of the shorelines of the east coast of Mare after first settlement. In no way can the infilling of site LPO023 be termed as a dense shell midden able to support entirely, with the fish catches, the food needs of even a small community, pointing to the existence of other components in the subsistence strategy. Although no new indication has been gained in this excavation, the hypothesis of a vegetable component present in the Lapita diet has to be advanced to explain the successful colonization of this region, with the cultivation of tubers and a possible arboricultural component (Kirch 1997), at least after the first few pioneering discovery voyages. Population numbers might never have been very high during the first centuries of settlement of Maré, but the indications gathered from site LPO023 indicate a regular occupation rather than a simple camp. The size of the seashore zone occupied during Lapita times, 
ranging from Padewia in the north to Kurin in the south, is over $5 \mathrm{~km}$ long, with good planting grounds at the foot of the cliffs, fresh water in different places, and the rich reef platform in front of the beach. Scattered low density occupations for about six to eight generations would probably not leave many more remains than the one visible today in the early layers in different parts of the dune. A very short occupation, as hypothesized for the excavated area of nearby site LPO020 of Patho (Sémah and Galipaud 1992), would not allow for the dispersion of probably over 40 pots in the small $100 \mathrm{~m}^{2}$ area studied on site LPO023.

The dates show an early occupation of site LPO023 of Kurin starting around 1050-1000 B.C., at the same general time period as the earliest Lapita sites of the Grande Terre (Sand 1997, 2000a). Data from the upper part of the in situ layer, whose occupation seems to end around 850-800 B.C., casts doubts on the late dates obtained for the neighboring site LPO020 of Patho, not confirming the production of dentate-stamped Lapita ware as late as 600-500 B.C. (Sémah and Galipaud 1992). Future studies will have to run other dates on that site to confirm the first results. Similar redatings conducted on Lapita sites of the Grande Terre have shown the absence of correspondence of dates from after 800-750 B.C. with in situ Lapita layers (Sand 1997), and in neighboring Lifou dentate-stamped pottery also seem to disappear completely after about 800 в.C. (Sand 1998a).

\section{CONCLUSION}

The preliminary excavations conducted on site LPO023 of Kurin on the east coast of Mare Island, have shown the presence of a well-preserved Lapita horizon on the upper part of the sand dune facing the sea. Analysis of the archaeological material has firmly placed the major occupation in the first settlement period of Southern Melanesia. Several different ${ }^{14} \mathrm{C}$ dates have enabled us to conclude that this part of the bay was occupied, probably continuously, between around 1000 B.C. and 850-800 B.C., at the same time period as the other Lapita sites of New Caledonia. These results allow us to demonstrate that the Loyalty Islands were part of the initial north-south settlement axis followed by the Austronesian potters discovering Remote Oceania. This progression was through central-southern Vanuatu, then the east coast of the Loyalties, before rapidly founding some major sites on the Grande Terre. This picture is in agreement with the data recently obtained in northern and central Vanuatu as well as the Grande Terre, finally concluding the quest for the first human settlement of this part of the Pacific.

Comparing it to other excavated sites in the region (e.g., Anderson and Clark 1999; Bedford 2000; Green 1976), LPO023 of Kurin is one of the best preserved Lapita sites discovered to date in Remote Oceania because the site has a very simple and well-preserved stratigraphy with features and rich material. It has not been affected by later disturbances related to horticultural practices, in contrast to many other early settlements (Kirch 1997), and no modern habitation is present in the immediate vicinity. All this makes it an ideal place for a very large-scale excavation in the future. This would allow one to gain a precise idea of the type of settlement patterns developed in Melanesia during the Lapita period, contributing to the wider understanding of the characteristics of the cultural complex in the Southern Lapita Province around 3000 years ago. 


\section{ACKNOWLEDGMENTS}

This research has been conducted by the New Caledonia Department of Archaeology (C. Sand, J. Bolé, A. Ouetcho), with the assistance of F. Wadra of the Yéwéné Cultural Centre of Maré. Funding was kindly allocated by the Loyalty Island Province, the New Caledonian Territory, and the French Ministry of Culture (Paris). We would like to thank the landowners of the site for authorization to excavate, and Wea Washetine's family for their hospitality. Thanks to two anonymous reviewers for constructive comments and to Asian Perspectives (P. V. Kirch) for the editing of the text, written by C. Sand. Responsibility for the views expressed in this paper remains that of the research team.

\section{NOTES}

1. Pottery remains the best chronological marker identified for the prehistory of New Caledonia. The chronology on Grande Terre (Main Island) starts with Lapita and paddle-impressed Podtanean pottery traditions at first settlement, before the development of different sets of incised pots during the rest of the first millennium B.C., named the Koné period. The first millennium A.D. is mainly characterized by handled pots of the Plum tradition, and the second millennium A.D. by thin Néra-tradition pots in southern Grande Terre, and mostly thick Oundjo-tradition pots in northern Grande Terre (Sand 19966).

\section{REFERENCES CITED}

Anderson, A., S. Bedford, G. Clark, I. Lilley, C. Sand, G. Summerhayes, and R. Torrence

2001 An inventory of Lapita sites containing dentate-stamped pottery, in The Archaeology of Lapita Dispersal in Oceania: 1-13, ed. G. Clark, A. Anderson, and T. Vunidilo. Terra Australis 17. Research School of Pacific and Asian Studies, Australian National University.

Anderson, A., and G. Clark

1999 The age of Lapita settlement in Fiji. Archaeology in Oceania 34:31-39.

Anson, D.

1983 Lapita pottery in the Bismarck archipelago and its affinities. Unpublished Ph.D. diss. University of Sydney.

BEDFORD, S.

2000 Pieces of the Vanuatu Puzzle: Archaeology of the North, South and Centre. Unpublished Ph.D. diss. Australian National University, Canberra.

Burley, D., D. E. Nelson, And R. Shutler Jr.

1999 A radiocarbon chronology for the Eastern Lapita frontier in Tonga. Archaeology in Oceania $34: 59-72$.

Coote, K., And C. SAND

1999 The conservation of Lapita pottery: Ignore it at your peril, in The Western Pacific, 5000 to 2000 B.P.: Colonisations and Transformations: 333-343, ed. J. C. Galipaud and J. Lilley. Paris: IRD.

Dubors, M. J.

1970 Géographie mythique et traditionnelle de Maré, Iles Loyauté, Nouvelle-Calédonie. Unpublished thesis at EPHE Ve section. Paris: Institut d'ethnologie.

FrimigacCI, D.

1980 Localisation éco-géographique et utilisation de l'espace de quelques sites Lapita de Nouvelle-Calédonie: essai d'interprétation. Journal de la Société des Océanistes 66-67:5-11.

1999 Où sont allés les potiers Lapita de Bourail? Remarques sur le site WKO001, in The Western Pacific, 5000 to 2000 B.P.: Colonisations and Transformations: 63-84, ed. J. C. Galipaud and J. Lilley. Paris: IRD. 
Galipaud, J. C.

1986 Prospection du site Lapita de Patho, île de Maré. La Case 6:11-20.

1990 The physical analysis of pottery from New Caledonia, in Lapita Design, Form and Composition: 134-142, ed. M. Spriggs. Occasional Papers in Prehistory 19. Canberra: Australian National University Press.

1996 New Caledonia: Some recent archaeological perspectives, in Oceanic Culture History. Essays in Honour of Roger Green: 297-305, ed. J. Davidson, G. Irwin, F. Leach, A. Pawley, and D. Brown. New Zealand Journal of Archaeology Special Publication.

1999 De quelques impressions. L'exemple de la poterie imprimée au battoir en Océanie lointaine, in The Western Pacific, 5000 to 2000 B.P.: Colonisations and Transformations: 531-541, ed. J. C. Galipaud and J. Lilley. Paris: IRD.

GifFord, E. W., AND R. Shutler JR.

1956 Archaeological Excavations in New Caledonia. Anthropological Records 18, University of California, Berkeley and Los Angeles.

Golson, J.

1971 Lapita Ware and its transformations, in Studies in Oceanic Culture History, vol. 2:67-76, ed. R. Green and M. Kelly. Pacific Anthropological Records 12, Honolulu.

Green, R. C.

1976 Lapita sites in the Santa Cruz group, in Southeast Solomon Island Cultural History: 245-265. The Royal Society of New Zealand Bulletin 11, Wellington.

1992 Definitions of the Lapita cultural complex and its non-ceramic component, in Poterie Lapita et peuplement: 7-20, ed. J. C. Galipaud. ORSTOM Editions, Nouméa.

GreEN, R. C., AND D. ANSON

2000 Excavations at Kainapirina (SAC), Watom Island, Papua New Guinea. New Zealand Journal of Archaeology 20 (1998):29-94.

KIRCH, P. V.

1997 The Lapita Peoples: Ancestors of the Oceanic World. Oxford: Blackwell Publishers.

SAND, C.

1995a Contribution à la reconstitution de la préhistoire des Îles Loyauté. Les Cahiers de l'Archéologie en Nouvelle-Calédonie 5.

1995 be temps d'avant: La préhistoire de la Nouvelle-Calédonie. Paris: L'Harmattan.

$1996 a$ Le début du peuplement austronésien de la Nouvelle-Calédonie: Données archéologiques récentes. Les Cahiers de l'Archéologie en Nouvelle-Calédonie 6.

$1996 b$ Recent developments in the study of New Caledonia's prehistory. Archaeology in Oceania 31:45-71.

1997 The chronology of Lapita ware in New Caledonia. Antiquity 71:539-547.

1998 a Recent archaeological research in the Loyalty Islands of New Caledonia. Asian Perspectives 37: 194-223.

1998 Archaeological report on localities WKO013A and WKO013B at the site of Lapita (Koné, New Caledonia). Journal of the Polynesian Society 107:7-33.

$1999 a$ The beginning of southern Melanesian prehistory: The St. Maurice-Vatcha Lapita site, New Caledonia. Journal of Field Archaeology 26:307-323.

$1999 b$ Lapita and non-Lapita ware during New Caledonia's first millenium of Austronesian settlement, in The Pacific from 5000 to 2000 B.P.: Colonisation and Transformations: 139159, ed. J. C. Galipaud and I. Lilley. Paris: IRD.

$2000 a$ The specificities of the "Southern Lapita Province": The New Caledonian case. Archaeology in Oceania $35: 20-33$.

$2000 b$ La datation du premier peuplement de Wallis et Futuna: Contribution à la définition de la chronologie Lapita en Polynésie occidentale. Journal de la Société des Océanistes 111:165172.

SAnd, C., J. Bolé, and A. Ouetcho

1999 Fichier d'inventaire des sites archéologiques et traditionnels de la Province des Îles Loyauté: Programme 1992-1997. Nouméa, Département Archéologie du Service des Musées et du Patrimoine de Nouvelle-Calédonie.

Sand, C., A. Ouetcho, J. Bolé, and D. Baret

2001 Evaluating the "Lapita smoke screen": Site SGO015 of Goro, an early Austronesian settlement on the south-east coast of New Caledonia's Grande Terre. New Zealand Journal of Archaeolog 22. 
SÉmah, A. M., AND J. C. Galipaud

1992 La fouille du site LAPITA de Patho (île de Maré, Nouvelle-Calédonie). Rapport d'Activité, Sciences Sociales, Archéologie, no. 5. Nouméa: ORSTOM.

Summerhayes, G.

2000 Lapita Interaction. Terra Australis 15. Research School of Pacific and Asian Studies. Australian National University, Canberra.

SWADling, P.

1986 Lapita shellfishing: Evidence from sites in the Reef Santa Cruz group, southeast Solomon Islands, in Traditional Fishing in the Pacific: 137-148, ed. A. Anderson. Pacific Anthropological Records 37, Honolulu.

\section{ABSTRACT}

Recent studies have dramatically shortened the chronology of Lapita pottery production in Remote Oceania, allowing this easily identifiable, decorated ceramic ware to be used as a precise temporal marker of first Austronesian settlement in this vast region. Unresolved questions about the precise date of settlement of the Loyalty Islands, located strategically between southern Vanuatu and the Grande Terre of New Caledonia, hinted at a clear picture of the direction and timing of the spread of the Lapita Cultural Complex in southern Melanesia. The results of the excavation of a Lapita site on Maré, in the south of the Loyalty Islands, are presented here, allowing firm placement of the first settlement phase of this region around 1050-1000 B.C., well in line with recent regional chronologies. KeYwords: Lapita; pottery; Remote Oceania; chronology. 